\title{
RESENHA
}

dO https://doi.org/10.22481/praxisedu.v16i40.6984

\section{FORMAÇÃO DE PROFESSORES: CONCEPÇÕES E POLÍTICAS}

\author{
TEACHER TRAINING: CONCEPTIONS AND POLICIES
}

FORMACIÓN DE PROFESORES: CONCEPCIONES Y POLÍTICAS

Learice Barreto Alencar

Universidade Católica de Brasília - Brasil

RESUMO: Resenha sobre o livro livro Formação de Professores: Concepções e Políticas.

Palavras chave: Formação de Professores. Políticas Públicas. Profissionalidade.

ABSTRACT: Review of the book Teacher Training: Conceptions and Policies.

Keywords: Teacher Education. Public policy. Professionalism.

RESUMEN: Revisión del libro Formación docente: conceptos y políticas.

Palabras clave: Formación docente. Políticas públicas. Profesionalidad.

"Formação de Professores: Concepções e Políticas" é uma obra de esforço coletivo, com a participação de trinta pesquisadores, composta por dezenove pesquisas reflexivas, que nos prendem a atenção devido a sua atualidade e validade das discussões propostas, todas ricamente respaldadas em um arcabouço teórico diversificado, o que nos proporciona uma visão ampliada devido aos diversos ângulos adotados.

Os estudos apresentados na obra Formação de Professores: Concepções e Políticas, estão agrupados por cinco eixos, da seguinte forma: Formação de Professores: Políticas, 
Concepções, Projetos e Profissionalidade ${ }^{1}$; A Construção da Profissionalidade Polivalente na Docência dos Anos Iniciais do Ensino Fundamental: das Concepções Oficiais aos Sentidos Atribuídos pelos Professores; Formação Continuada de Professores da Educação Básica; Profissionalidade e Formação Docente para a Educação Profissional. A base estruturante do conjunto dos estudos é a formação de professores, considerando os conflitos que demarcam interesses estratégicos, e também os paradigmas de conhecimento que circundam o assunto.

As pesquisas estão agrupadas em eixos, porém, é possível aprofundar os estudos com as pesquisas inter-relacionadas, independentemente de eixos, assim a análise será apresentada por conteúdo para demonstrar com maior evidência os temas pesquisados.

Discute-se primeiramente a formação dos professores sob a perspectiva das políticas, concepções, projetos e profissionalidade, sendo a primeira pesquisa O Currículo e a Formação do Pedagogo: Percepção dos Estudantes. Buscou-se compreender a percepção dos estudantes de Pedagogia da Universidade de Brasília, sobre o currículo de formação inicial, com o objetivo de perceber qual identidade de pedagogo é construída nesta instituição, a pesquisa indica que apesar de possuir um currículo inovador, o curso precisa ser organizado, pois a maioria dos participantes tem críticas sobre a amplitude do currículo e se sentem confusos durante o processo formativo.

Outra pesquisa que complementa o assunto trata dos Currículos dos Cursos de Formação e a Construção da Profissionalidade Polivalente: uma Análise dos Cursos de Pedagogia do Entorno do Distrito Federal. Este capítulo se dá a compreender a construção da profissionalidade dos pedagogos, que têm como habilitação e exercício a incumbência de lecionar nas diversas áreas de conhecimento do currículo da educação básica. A pesquisa evidencia que não há um consenso sobre o uso do termo polivalente, muitas vezes, usa-se o termo multidisciplinary. Essa questão só problematiza a diferenciação e distanciamento entre formação e atuação docente, pois ambos estão ligados ao sentido quantitativo, o que tem perdurado na história da educação brasileira.

Na pesquisa sobre Residência Docente cujo objetivo é definir o que é a residência docente e identificar a sua necessidade na formação dos professores e na inserção do profissional docente, aponta-se experiências existentes e quais elementos centrais para se pensar em uma proposta de residência. Fica notório o quanto esta atividade integrada ao

\footnotetext{
${ }^{1}$ A obra cita o conceito de Roldão (2005) para profissionalidade, como sendo um conjunto de atributos, construídos socialmente, que distinguem muitos tipos de atividades igualmente relevantes e valiosas de uma profissão.
} 
currículo de formação docente o tornaria um profissional mais completo e realmente exercitando a práxis.

Outra proposta enriquecedora para a formação inicial docente é apresentada na pesquisa O PIBID como Componente Curricular na Formação de Professores: Limites e Possibilidades, em que se analisa como proposta curricular com possibilidades de institucionalização nas instituições de formação de professores na formação inicial, como modelo de residência pedagógica. Apresenta-se a residência pedagógica como um espectro maior, o da política pública de estado.

Sobre a construção da profissionalidade polivalente, a pesquisa As concepções de Extensão Universitária e a Formação Docente: Algumas Reflexões, discute as concepções de extensão universitária enquanto possibilitadora de uma formação docente ancorada nos sentidos da crítica e da emancipação na construção do conhecimento, desde que a Universidade, principalmente a pública, alicerce seus trabalhos na indissociabilidade pesquisa, ensino e extensão. O estudo é bastante pertinente quando analisado o perfil do professor em exercício, o quanto lhe falta de capacidade de vincular teoria e prática, A extensão universitária é um espaço privilegiado para o desenvolvimento dessa praxis necessária à sala de aula.

A questão da profissionalidade docente ainda é mais preocupante na educação profissional, pois admite o bacharelado. A pesquisa Aspectos da Profissionalidade do Bacharel Docente na Educação Básica, Técnica e Tecnológica: o Caso do IFTM - Campus Paracatu, buscou compreender o processo de constituição da profissionalidade de professores bacharéis do Instituto Federal de Educação, Ciência e Tecnologia do Triângulo Mineiro. Com ênfase nos distintos percursos formativos e no processo de aprendizagem da docência - em um contexto político/educacional de construção identitária que a instituição vivência, fica evidenciado, portanto, que há muito o que ser pesquisado, compreendido e investido na profissionalidade do bacharel, tema pouco explorado ainda na educação brasileira.

A pesquisa sobre A Formação Stricto Sensu e o Trabalho Docente da Educação Básica: uma Realidade no Distrito Federal, levantou os dados sobre os professores com títulos de mestres e doutores que estão no exercício do magistério e a diferença desta formação em sua prática e carreira. Pode-se observar que no plano de carreira do magistério local não há necessidade de o docente cursar mestrado e/ou doutorado, mais que isso, não há incentivo para fazê-lo sob o ponto de vista de remuneração, pois o valor adicional calculado é irrisório. Contudo, os que se propõem a fazer se tornam referência, rompem com modelos e causam estranhamento dos pares e dele mesmo, como concluem as autoras da pesquisa. 
A formação continuada de docentes é locus onde se percebe as descontinuidades dos programas ofertados. A pesquisa sobre Fortalecimento do Ensino Médio/PNEM, buscou revelar os sentidos da formação continuada, compreender os processos que são muito particulares ao professor e ao mesmo tempo constitui a totalidade desse movimento. Este estudo ratifica a necessidade de políticas de formação continuada que contemplem a realidade do Ensino Médio e que tenham continuidade, sobretudo pautadas na valorização e melhorias das condições do trabalho e da carreira.

Além da descontinuidade das políticas de formação de professores, tem-se também os problemas de evasão nos programas já existentes, a exemplo de Física, Matemática, Química, Ciências Biológica e Geografia, como demonstra a pesquisa Entre a Escassez e a Evasão: a Formação de Professores em Instituições Federais de Educação Profissional Tecnológica. A pesquisa se propõe a discutir questões acerca da evasão nos cursos de formação de professores nos Institutos Federais de Educação, Ciência e Tecnologia.

Uma pesquisa se destaca nessa obra: A Coordenação Pedagógica na Jornada de Trabalho como Espaço-Tempo para o Planejamento, Formação e Valorização Docente no Distrito Federal. Este capítulo teve como objetivo identificar quais os mecanismos legais instituídos sobre a jornada de trabalho do professor do DF e se eles contribuem para a viabilização da valorização professional. Ficou evidenciado que, apesar das condições de trabalho se apresentarem nos documentos normativos, o trabalho docente ainda não é coletivo e tem se tornado cada vez mais individualizado, competitivo e intensificado. O que me leva a concordar com os autores, uma vez que é o que vivêncio na prática diária, o uso da coordenação pedagógica para o trabalho coletivo, sendo realizada, na maioria das vezes, em casa, individualmente.

Essa coletânea de pesquisas apresenta, por meio de vinte e um autores, um posicionamento crítico sobre a política educacional brasileira, especificamente no universo de formação de professores, deixando evidente as diversas frentes que tem a área. Contudo que nenhuma, seja formação inicial, continuada ou de extensão, encontra-se consolidada, muitas ainda sob o risco de descontinuidade, como é o caso da residência pedagógica. As reflexões realizadas, apontam poucos avanços, como a proposição de inserção do PIBID como componente curricular para o curso de Pedagogia. Há alguns retrocessos, como evidenciado nas respostas dos estudantes do curso, que sentem que o currículo é muito amplo, dificultando a construção da identidade do pedagogo. Os insumos das pesquisas poderão colaborar para o fortalecimento dos estudos futuros e de políticas para melhoria da educação brasileira. 
Além do seu valor acadêmico para a área educacional brasileira, a obra é de leitura empolgante, que nos mostrando uma profunda análise do contexto de formação de professores no Brasil e sob diversas óticas. São apontados caminhos de certezas e incertezas, de possibilidades de ações e estudos. Pelos temas das pesquisas ora elencados o leitor poderá, se iniciante no assunto, obter um adequado alinhamento das temáticas com relação a importância para os pesquisadores brasileiros; se já inserido no contexto abordado, encontrará motivações para maiores aprofundamentos, discussões e engajamento.

\section{REFERÊNCIA}

SILVA, Kátia Augusta Curado Pinheiro Cordeiro da; CASSETTARI... [et. al] (Org.).

Formação de professores: Concepções e Políticas. 1. ed. Jundiaí SP: Editora Paco, 2017.

\section{SOBRE A AUTORA:}

\section{Learice Barreto Alencar}

Mestranda em Educação pela Universidade Católica de Brasília (UCB); aluna do Programa de Pós-Graduação Stricto Sensu em Educação da Universidade Católica de Brasília. E-mail: learice.alencar@gmail.com.

iD http://orcid.org/0000-0002-7236-7106 